\title{
Muscle Weakness Left-Sided, CTCAE
}

National Cancer Institute

\section{Source}

National Cancer Institute. Muscle Weakness Left-Sided, CT CAE. NCI Thesaurus. Code C143681.

A disorder characterized by a reduction in the strength of the muscles on the left side of the body. 